\title{
Overcoming inequalities in teaching and learning
}

\author{
P. T. M. Marope ${ }^{1}$
}

Published online: 25 August 2015

(C) UNESCO IBE 2015

This special issue on the theme "Overcoming inequalities in teaching and learning" comes at a pivotal time. The United Nations post-2015 Sustainable Development Goals (SDGs), agreed to in September 2015, include education as a key pillar. For many countries and regions, especially developing ones, the shortage of human resources with the right kind, level, and mix of competencies (i.e., knowledge, skills, affects, and the application thereof) is among the most critical constraints to transitioning to higher levels of development. Thus, an overarching ambition of the sustainable development framework is to ensure no one is left behind by 2030. From an education perspective, this ambition is expected to be achieved both in terms of getting all children into school, as well as ensuring they are learning once they are in school.

The articles in this special issue aim to contribute to our understanding of how to enhance teaching and learning in ways that improve learning for all children, regardless of their wealth, gender, or where they live. The articles are based on selected background papers and related analyses for the 2013/4 Education for All Global Monitoring Report (GMR) on the theme "Teaching and learning: Achieving quality Education for All".

The 2013/4 GMR, directed by Pauline Rose, guest editor of this special issue, highlights that 250 million children are not learning the basics, even though at least half of them have spent a minimum of 4 years in school (UNESCO 2014). As Irina Bokova, the DirectorGeneral of UNESCO, states in her Foreword to the report: "An education system is only as good as its teachers. Unlocking teachers' potential is essential to enhancing the quality of learning. Evidence shows that education quality improves when teachers are supported-it deteriorates if they are not".

The articles in this special issue span a range of perspectives on the importance of reforms to support improving the quality of teachers and teaching in order to overcome the learning crisis. Articles that present innovative analyses of large-scale learning

P. T. M. Marope

ibe.prospects@unesco.org

1 UNESCO International Bureau of Education, C.P. 199, 1211 Geneva 20, Switzerland 
assessments, including PISA and TIMSS, are complemented by more detailed analyses of the patterns of learning inequalities in particular country contexts, including using Young Lives data in Ethiopia, Peru, India, and Vietnam; and in India and Pakistan, using citizenled Annual Status of Education Report (ASER) assessments.

All of these articles confirm an overarching concern: children from disadvantaged backgrounds are least likely to be learning. The evidence also identifies that improving school and teacher quality is vital, but that reforms in these areas are, alone, unlikely to be sufficient. Rather, to overcome the "learning crisis", there is an urgent need to tackle disadvantages that children face before they even start school.

As the 2013/4 EFA GMR highlights, the learning crises requires that we make considerably greater efforts to unlock the potential of teachers. Further, articles in this special issue demonstrate that several nations-particularly some of the world's poorest countries-need many more teachers in order to give all children access to a high-quality education. The shortfall in the number of teachers is unlikely to change unless policymakers strengthen education plans in ways that seriously address the problem. To date, too many plans pay insufficient attention to expanding the teaching force. Even fewer identify strategies to improve the quality of education or to support teachers in their efforts to overcome inequalities in learning.

The adoption of the SDGs, in which education plays a central role, is repositioning the issues of teaching and learning, placing them at the forefront of reform agendas. The International Bureau of Education (IBE), whose work focuses on strengthening the capacity of education systems to equitably provide high-quality education and effective learning opportunities, believes that this push is critical to bridging the gap between education and development and ensuring equitable and inclusive quality education by 2030. Also, as a UNESCO global center of excellence in curriculum, learning and assessment, the IBE is well positioned to lead the reform agenda, by the setting of norms and standards for well-balanced curricula, learning practices, and assessment methods that countries can adapt and operationalize in their respective contexts and circumstances.

Effective reforms that promote equitable learning will require policymakers and educators to identify teachers themselves as part of the solution and to consult them on the design of reforms. Teacher unions have a potentially important role to play in this regard. When systems engage teachers, evidence presented in the special issue shows that they have successfully helped develop strategies to address the problems that some children face in the classroom, such as an inappropriate language of instruction, which holds back their learning.

The IBE strongly believes that promoting equitable learning also requires providing teachers with the necessary tools to translate the goals and objectives of education systems into learning outcomes. These tools include curricula that package the essential and desirable knowledge, skills, affects, and technology savvy—and the application of these elements - that children should acquire through education. In giving effect to learning and in ensuring consistent alignment of learning with social aspirations and development goals, the teacher and the curriculum together become key to improved quality and equity in education.

It is encouraging that the post-2015 goals evince a commitment to leave no one behind. As the articles in this special issue emphasize, action needs to be taken now to make sure such commitments to learning are met by 2030. This requires paying special attention to supporting teachers in ways that allow them to give all children in their classrooms an equal chance to learn. 


\section{Reference}

UNESCO (2014). Teaching and learning: Achieving quality for all. Education for All: Global Monitoring Report. Paris: UNESCO. 